\title{
Interface between Pharmacotherapy and Genes in Human Obesity
}

\author{
Annalouise O'Connor Andrew G. Swick \\ UNC Chapel Hill Nutrition Research Institute, Kannapolis, N.C., USA
}

\section{Key Words}

Obesity · Weight loss drugs . Pharmacogenetics .

Pharmacogenomics

\begin{abstract}
Obesity is a polygenic chronic condition, and dysregulation in multiple underlying energy balance processes drives the obese phenotype. Lifestyle changes can be difficult to sustain long term, and anti-obesity drugs can be an advantageous component of a successful weight loss plan. However, due to lack of efficacy or adverse safety profiles, there is currently a limited selection of anti-obesity drugs on the market. This, coupled with the notable interindividual variability in efficacy of approved treatments, represents a significant unmet medical need. In this review, we will highlight this variability in weight loss response to these existing anti-obesity compounds and discuss how underpinning genetic variation is associated with weight loss outcomes. Existing research in the field of pharmacogenomics and obesity drugs will be highlighted, as will possibilities for future focus. We will conclude by exploring examples of successful pharmacogenomics studies, and also by asking how pharmacogenomics can be built into the drug development pipeline for the benefit of patients and pharmaceutical companies alike.
\end{abstract}

(c) 2013 S. Karger AG, Basel

\section{KARGER}

C 2013 S. Karger AG, Basel

0001-5652/13/0754-0116\$38.00/0

E-Mail karger@karger.com

www.karger.com/hhe

\section{Introduction}

Obesity rates have risen sharply in recent years, doubling globally since 1980 [1]. More than 1 in 10 of the world's population is now considered obese [1], and obesity and overweight affect two thirds of adults in the US [2]. Prevalence of overweight and obesity is predicted to reach $86.3 \%$ by 2030 in the US if current trends continue [3]. This is alarming considering the toll which obesity exacts on quality of life and mortality. In fact, obesity is now considered the number one cause of preventable death in the US. Approximately 300 million adults die each year as a result of being overweight or obese [1]. Furthermore, obesity drives chronic diseases and lies at the root of $44 \%$ of the burden of diabetes, $23 \%$ of ischemic heart disease burden and $7-41 \%$ of the burden of specific cancers [1]. If obesity rates continue unabated, the number of new cases of chronic conditions such as type 2 diabetes, coronary heart disease, stroke, hypertension and arthritis is predicted to grow substantially (10-fold increase between 2010 and 2020) [2].

At its most fundamental level, overweight and obesity develop secondary to an imbalance between energy consumed and energy expended. Although simple when reduced to these terms, a highly complex web of social, dietary, environmental and genetic factors underpins energy balance regulation [4]. This results in a highly 
heterogeneous set of factors driving a phenotype [increased body mass index (BMI) and adiposity] which on the surface appears similar between individuals. Individual genetic factors govern the risk of obesity and the ability of an individual to robustly defend a healthy body weight in an obesogenic environment. Data from twin and family studies suggest that $40-70 \%$ of interindividual body weight variability can be attributed to genetics [5]. However, unraveling the genetics of obesity is proving complex. Although extremely rare forms of monogenic obesity are documented, for example genetic leptin deficiency which responds to leptin treatment [6], in general, obesity is not the result of a single gene defect and is instead a polygenic condition with networks of gene-gene and gene-environment interactions. The advent of genome-wide association studies (GWAS) has added significantly to our knowledge of genetic factors underlying obesity and has led to the identification of novel loci linked with overall adiposity and visceral fat accumulation [7]. However, consistent with the multi-factorial nature of obesity development, individual single nucleotide polymorphisms (SNPs) identified by GWAS to date account for a very small percentage of phenotypic variance in test populations. For example, SNPs in Fat Mass and Obesity (FTO) and melanocortin-4 receptor (MC4R), which are among the most robustly replicated, account for less than $2 \%$ in adult BMI variance $[8,9]$.

\section{Search Criteria}

Literature searches were performed using PubMed for all original articles published using 'genotype', 'genetics', 'genomics', 'SNPs', 'pharmacogenetics' and 'pharmacogenomics' combined with 'weight loss', 'obesity', 'sibutramine', 'orlistat', 'phentermine', 'lorcaserin', 'Belviq', 'topiramate', 'Qsymia', 'GLP-1 receptor agonist', 'rimonabant' and 'CB-1 blockers'. All articles identified were English language full-text papers. To ensure that all relevant literature was captured, reference lists of previous reviews from peerreviewed journals were searched for additional papers. Additionally, the authors drew from their knowledge of the literature in this field.

\section{Weight Loss Recommendations for Obesity}

Overweight and obese individuals are encouraged to lose weight. More specifically, it is recommended that patients with obesity $(\mathrm{BMI}>30)$ lose at least $10 \%$ of their body weight as even this modest reduction has measurable benefits with respect to metabolic health and improvement of obesity-associated comorbidities [10]. Life- style modification, such as increasing physical activity, decreasing energy intake, and cognitive behavioral therapy, is the preferred first line of treatment for obesity. Although the value of lifestyle interventions has been established [11-13], adherence to lifestyle changes can be problematic in the longer term. In general, even relatively small body weight losses are difficult to maintain and it has been estimated that significant weight regain occurs in $80-90 \%$ of individuals [14]. Pharmacological treatment options are indicated for individuals with a BMI $>30$ (obese) or those with a BMI >25 (overweight) with existing comorbidities such as diabetes, dyslipidemia or hypertension [10]. To improve weight loss outcomes, positioning pharmacological treatments in an individual's weight loss plan alongside diet and exercise may enhance body weight loss and be particularly beneficial for those unable to lose sufficient weight and/or maintain a reduced weight (i.e. 10\%) through lifestyle modification alone.

\section{Pharmacological Treatment of Obesity}

Although the magnitude of the obesity epidemic continues to increase, there is a relative lack of efficacious pharmacotherapies approved for the treatment of this chronic condition, and thus there is a tremendous unmet medical need. Despite the fact that many anti-obesity compounds have made it to various stages of drug development over the past 2-3 decades, the vast majority have not been approved and thus not marketed, as a result of insufficient efficacy and/or adverse side effects. Currently, only 3 drugs [orlistat (Xenical, Alli), lorcaserin $\mathrm{HCl}$ (Belviq), phentermine and topiramate extended release (Qsymia)] are approved for continuous use in the US, and $1 \mathrm{drug}$, phentermine, is approved for short-term use (up to 12 weeks) (table 1 ). In comparison, $~ 34$ drugs are approved and marketed for the treatment of diabetes [15] and $\sim 79$ for hypertension [16]. Several drugs such as sibutramine (US and Europe) and rimonabant (Europe) (table 1) have been marketed previously for weight loss, but have been withdrawn due to an inadequate cardiovascular disease safety profile or adverse neuropsychiatric symptoms, respectively. In addition, other pharmacotherapies are prescribed off-label for the treatment of obesity in the USA (table 1).

Alongside the relative dearth of pharmacological treatments for obesity, issues of compliance are important to consider. Meta-analyses of studies examining the weight loss effects of orlistat and sibutramine (Reductil, 
Table 1. Weight loss drugs currently available on the market, previously withdrawn or used off label for weight reduction

\begin{tabular}{|c|c|c|c|}
\hline Drug details & Proposed mechanism of action & Efficacy & Adverse effects \\
\hline \multicolumn{4}{|c|}{ Currently marketed weight loss drugs } \\
\hline $\begin{array}{l}\text { Phentermine } \\
\text { hydrochloride } \\
\text { (Adipex- } \mathrm{P}^{\circledR}, \text { Teva) }\end{array}$ & $\begin{array}{l}\text { Sympathomimetic amine. Acts } \\
\text { centrally to increase dopamine, } \\
\text { norepinephrine and serotonin activity } \\
\text { resulting in reduced food intake and } \\
\text { increased energy expenditure [80]. }\end{array}$ & $\begin{array}{l}95.8 \text { and } 62.5 \% \text { of subjects taking } \\
\text { phentermine attained } 10 \text { and } 5 \% \text { weight } \\
\text { loss, respectively, following } 12 \text { weeks of } \\
\text { treatment (compared with } 20.8 \text { and } 4.7 \% \\
\text { of subjects in the placebo group) [81]. }\end{array}$ & $\begin{array}{l}\text { Insomnia, anxiety and other central } \\
\text { nervous system side effects, tachycardia, } \\
\text { elevated blood pressure, palpitations } \\
\text { and gastrointestinal effects. Associated } \\
\text { with increased tolerance and } \\
\text { dependency with long-term use. }\end{array}$ \\
\hline $\begin{array}{l}\text { Phentermine } \\
\text { hydrochloride/ } \\
\text { topiramate } \\
\text { extended release } \\
\text { (Qysmia }^{\mathrm{TM}} \text {, Vivus) }\end{array}$ & $\begin{array}{l}\text { Topiramate, originally developed as an } \\
\text { anti-epileptic, has been shown to } \\
\text { reduce body weight, although the } \\
\text { mechanism of action is not exactly } \\
\text { clear. Phentermine is a } \\
\text { sympathomimetic amine (see above). } \\
\text { Phentermine and topiramate are } \\
\text { effective at inducing weight loss alone; } \\
\text { however, adverse side effects prohibit } \\
\text { individual long-term use. The lowered } \\
\text { doses used in this combination } \\
\text { facilitate weight loss while maintaining } \\
\text { an adequate safety profile. }\end{array}$ & $\begin{array}{l}\text { Approximately } 62 \% \text { of subjects taking } \\
7.5 / 46 \text { mg (phentermine/topiramate) lost } \\
5 \% \text { of their body weight and } 37 \% \text { lost } 10 \% \\
\text { of their body weight during the } 1 \text {-year } \\
\text { treatment period (compared with } 21 \text { and } \\
7 \% \text { in the placebo group) [18]. }\end{array}$ & $\begin{array}{l}\text { Dry mouth, constipation, dysgeusia, } \\
\text { paresthesia, insomnia, dizziness and } \\
\text { irritability [18]. Approved with Risk } \\
\text { Evaluation and Mitigation Strategy } \\
\text { (REMS) based on an increased risk to } \\
\text { infants of developing orofacial clefts if } \\
\text { exposed during the 1st trimester [82]. }\end{array}$ \\
\hline $\begin{array}{l}\text { Lorcaserin } \\
\text { hydrochloride } \\
\text { (Belviq, Arena, } \\
\text { Eisai Inc.) }\end{array}$ & $\begin{array}{l}\text { Selective serotonin } 2 \mathrm{C}\left(5-\mathrm{HT}_{2 \mathrm{C}}\right) \\
\text { receptor agonist which acts centrally } \\
\text { to increase satiety and decrease food } \\
\text { intake. }\end{array}$ & $\begin{array}{l}47.2 \% \text { of subjects lost at least } 5 \% \text { of body } \\
\text { weight compared with } 20-25 \% \text { of subjects } \\
\text { taking placebo following } 1 \text { year of } \\
\text { treatment }[20,28] .22 .6 \% \text { of subjects taking } \\
\text { Belviq lost at least } 10 \% \text { of their body } \\
\text { weight compared with } 7.7-9.7 \% \text { of } \\
\text { subjects in the placebo group }[20,28] .\end{array}$ & $\begin{array}{l}\text { Upper respiratory infections, headache, } \\
\text { dizziness, nasopharyngitis and nausea } \\
\text { [28]. }\end{array}$ \\
\hline
\end{tabular}

Weight loss drugs withdrawn from the market after approval

\begin{tabular}{|c|c|c|c|}
\hline $\begin{array}{l}\text { Sibutramine } \\
\text { hydrochloride } \\
\text { (Meridia, Abbott) }\end{array}$ & $\begin{array}{l}\text { Selective serotonin and } \\
\text { norepinephrine reuptake inhibitor. } \\
\text { Raises hypothalamic serotonin and } \\
\text { noradrenaline concentrations by } \\
\text { inhibiting their reuptake which } \\
\text { results in decreased food intake. } \\
\text { Revoked from EU and USA markets } \\
\text { due to cardiovascular safety concerns. }\end{array}$ & $\begin{array}{l}5 \text { and } 10 \% \text { body weight loss at } 1 \text { year was } \\
\text { attained by } 42 \text { and } 25 \% \text { of individuals, } \\
\text { respectively [26]. }\end{array}$ & $\begin{array}{l}\text { Increased blood pressure and pulse rate, } \\
\text { constipation, dry mouth and insomnia. }\end{array}$ \\
\hline $\begin{array}{l}\text { Rimonabant } \\
\text { (Acomplia, } \\
\text { Sanofi-Aventis) }\end{array}$ & $\begin{array}{l}\text { CB1 antagonist. Acts centrally to } \\
\text { block CB1 receptors resulting in } \\
\text { reduced food intake. }\end{array}$ & $\begin{array}{l}48.6-50.9 \% \text { of subjects taking rimonabant } \\
\text { lost } 5 \% \text { of their body weight in } 1 \text { year } \\
\text { compared with } 19.2-20 \% \text { of subjects } \\
\text { taking placebo. } 25.2-27.4 \% \text { of rimonabant } \\
\text { subjects lost at least } 10 \% \text { body weight in } 1 \\
\text { year compared with } 7.3-8.5 \% \text { in the } \\
\text { placebo group }[19,29] \text {. }\end{array}$ & $\begin{array}{l}\text { Failed to obtain FDA approval and was } \\
\text { withdrawn from the European market } \\
\text { due to adverse psychiatric side effects } \\
\text { which included increased depression, } \\
\text { anxiety and suicidal ideation [83]. Other } \\
\text { side effects noted in phase III trials } \\
\text { included nausea, dizziness, arthralgia } \\
\text { and diarrhea [19]. }\end{array}$ \\
\hline
\end{tabular}

Peptide-based drugs used off-label for weight loss

Glucagon-like peptide Activates GLP-1 receptors in the 1 receptor (GLP-1R) central nervous system to reduce food agonist-based intake.

therapies, e.g.

exenatide

(Bydureon, Amylin;

Byetta, Amylin)
Meta-analysis of randomized controlled trials investigating the impact of GLP-1R agonists on weight loss reported treatment induced greater weight loss than placebo in individuals with and without diabetes. Weight loss ranged from -0.2 to $-7.2 \mathrm{~kg}$ [17].
Hypoglycemia, nausea, diarrhea and vomiting. 
Meridia, Sibutrex) report that attrition rates can reach $50 \%$ [17]. This is similar to rates reported in large trials of phentermine and topiramate [18], rimonabant (Acomplia) [19] and lorcaserin [20]. Using pharmacy purchasing information from a large Health Maintenance Organization (HMO) serving over 1 million individuals, another group reports that adherence to therapy (orlistat, sibutramine) was substantially lower than that reported in clinical trials [21]. Although reasons for this noncompliance were not assessed due to the study design, age, gender or baseline BMI were not significantly associated with adherence [21]. A closer examination of published drug trials (rimonabant, sibutramine, orlistat) shows that among the top reasons for withdrawal/dropout from the trials were adverse effects, followed by patient request and noncompliance [18-20,22]. Additionally, although not specific for anti-obesity drugs, lack of efficacy is often noted as a reason for withdrawal and noncompliance. These results highlight the need for efficacious pharmacotherapies targeting obesity which will be taken long term by patients.

\section{Variability in Response to Weight Loss Drugs - A Justification for a Pharmacogenomics Approach}

In an obese population, the underlying genetic and molecular processes promoting weight gain can vary significantly between individuals despite general phenotypic similarities within the group [23]. This has a substantial impact on potential therapeutic efficacy of pharmacological treatments which often target a single specific energy balance regulatory mechanism. Additionally, common genetic variation may alter the response to pharmacotherapy even if this variation is not associated with the risk of developing the disease itself [24]. Indeed, the weight loss response to drug treatments for obesity varies considerably. It has been noted that the overall data reporting quality of obesity drug trials is low, with poor and inconsistent reporting of standard error and standard deviation making it difficult to assess overall variability in weight loss response [25]. However, the number of subjects who achieve the goal weight loss during treatment is telling, with the majority of drug trials reporting that less than half of drug-treated participants met the $5 \%$ weight loss target, and a smaller proportion attain the more ideal $10 \%$ body weight loss.

The response to sibutramine treatment, for example, is known to be highly variable. Five and $10 \%$ body weight loss at 1 year was attained by 42 and $25 \%$ of individuals,

Pharmacotherapy and Genes in Human Obesity respectively [26]. In a 6-month study examining the efficacy of orlistat, $37 \%$ of subjects in the orlistat treatment group achieved the $10 \%$ weight loss goal, compared with $19 \%$ of subjects taking placebo [27]. A trial examining the efficacy of lorcaserin $\mathrm{HCl}$ reported that $47.2 \%$ of subjects lost at least $5 \%$ body weight compared with $25 \%$ of subjects taking placebo following 1 year of treatment [20]. $22.6 \%$ of subjects taking lorcaserin $\mathrm{HCl}$ lost at least $10 \%$ of their body weight compared with $9.7 \%$ of subjects in the placebo group [20]. These results agreed strongly with those of an earlier study which reported that $47.5 \%$ of subjects in the lorcaserin $\mathrm{HCl}$ arm lost at least $5 \%$ of body weight compared with $20.3 \%$ in the placebo group, and $22.6 \%$ of subjects taking lorcaserin $\mathrm{HCl}$ lost at least $10 \%$ body weight compared with $7.7 \%$ in the placebo group [28]. In the Phase III trial (CONQUER Trial) examining phentermine/topiramate extended release, $62 \%$ of subjects receiving a 7.5/46.0 $\mathrm{mg}$ (phentermine/topiramate) dose and $70 \%$ of subjects receiving a higher dose (15/92 $\mathrm{mg}$ ) achieved at least $5 \%$ body weight loss over the 1 -year treatment period compared with $21 \%$ in the placebo group. Seven percent in the placebo group, $37 \%$ in the $7.5 / 46 \mathrm{mg}$ and $48 \%$ in the $15 / 92 \mathrm{mg}$ group achieved greater than $10 \%$ weight loss [18]. Furthermore, in the RIONorth America Study which examined rimonabant-induced weight loss, $48.6 \%$ of subjects taking rimonabant lost $5 \%$ of their body weight versus $20 \%$ of subjects taking placebo at 1 year. $25.2 \%$ of rimonabant subjects lost at least $10 \%$ versus $8.5 \%$ in the placebo group [29]. In the European Study (RIO-Europe), 50.9\% of subjects in the rimonabant group lost over 5\% and $27.4 \%$ lost over $10 \%$ at 1 year compared with 19.2 and $7.3 \%$ in the placebo group (5 and 10\% weight loss, respectively) [19]. The lack of clinically meaningful weight loss in a large proportion (typically over $50 \%$ ) of drug-treated patients coupled with the risks of adverse effects (both known and potentially unknown that may become evident after approval with longer-term use) highlights the importance of identifying and targeting patients who will respond best to a specific pharmacotherapy.

It is reasonable to conclude that underlying genetic differences contribute to variability in response to treatment. This has led to a great deal of interest in the influence of genetics on responses to pharmacological interventions and to the study of pharmacogenomics. The internationally harmonized definition of pharmacogenomics (PGx) is the 'study of variations of DNA and RNA characteristics as related to drug response'. Pharmacogenetics (PGt) is considered a subset of this and is defined as 'the study of variations in DNA sequence as related to 
drug response' [30]. As interindividual genetic differences have the capacity to influence all facets of a disease state, from pathogenesis to therapy, the Food and Drug Administration (FDA) has outlined three broad categories with relevance for drug development and pharmacotherapy: (1) genes relevant to the drug's pharmacokinetics [absorption, distribution, metabolism (including formation of active metabolites) and excretion (ADME)]; (2) genes that affect the drug's intended and unintended targets and therefore its effect on these targets, and (3) genes that predict the occurrence of disease development (e.g. genes that predict likelihood of tumor development or metastasis), sometimes called prognostic markers [31]. The value of PGx as stated by the FDA is to make drugs safer and more effective by identifying individuals who are most at risk for drug-induced adverse effects (safety PGx), are most likely to have an efficacious response or benefit from a genotype-modified dose or dosing interval (efficacy PGx) [31].

Considering the variability in weight loss response to pharmacotherapy, identification of drug-sensitive genotypes is important for several reasons. Targeted interventions will reduce unnecessary potential for adverse events in individuals unlikely to respond and may increase compliance with therapies as individuals will see a benefit to continued treatment. Additionally, a more focused approach may improve the cost/benefit and risk/benefit ratios of these treatments. PGt is becoming more prevalent in other health areas related to obesity, such as antipsychotic-induced weight gain (for review, see [32, 33]).

\section{Safety and Efficacy PGx in Relation to Obesity Pharmacotherapies}

\section{Efficacy PGx and Sibutramine}

Sibutramine is a serotonergic and noradrenergic reuptake inhibitor and acts centrally on 5-HT pathways, inhibiting the reuptake of serotonin and noradrenaline released from hypothalamic neurons [34]. Sibutramine is also associated with an increase in plasma epinephrine. The transmembrane 5-HT receptors signal to the intracellular environment through heterotrimeric guanine nucleotide-binding proteins (G-proteins). Activation of $5-\mathrm{HT}_{2 \mathrm{C}}$ receptors in particular leads to hypophagia [35]. Considering that weight loss responsiveness is highly variable and the causes are unknown, several researchers have sought to segment responders and nonresponders to sibutramine based on genotype at key genes in sibutramine target pathways. Although not currently available in the US or Europe, sibutramine is the most heavily studied anti-obesity agent in relation to PGx and provides an example of choosing candidate genes based on proposed target pathways.

\section{GNB3}

The GNB3 gene encodes the G $\beta 3$ subunit of heterotrimeric $\mathrm{G}$ proteins. A polymorphism in this gene (rs5443), commonly known as the C825T variant, has received much attention within the context of obesity [36-38]. This is a synonymous SNP consisting of a substitution for $\mathrm{C}$ by $\mathrm{T}$ at position 825 in exon 10 . The $\mathrm{T}$ allele is associated with a splice variant which is biologically active and linked with enhanced signal transduction [39]. Genotype at this SNP has also been associated with weight loss responsiveness to sibutramine. The initial report of this came from Hauner et al. [40] who retrospectively genotyped obese subjects $(\mathrm{n}=111)$ who had participated in a 54 -week randomized controlled trial of sibutramine versus control. All subjects received dietetic support, access to educational sessions and encouragement to increase physical activity. The $825 \mathrm{~T}$ allele was found at a frequency of $35.1 \%$ which is comparable to that reported previously in obese Caucasian subjects [36, 41]. A strong effect of sibutramine was seen in the CC genotype group, wherein individuals in this group lost significantly more weight than the T allele carriers (TC and TT) $(7.2 \pm 2.2 \mathrm{~kg}$ compared with $4.1 \pm 2.0 \mathrm{~kg}$ ). The OR for 5 and $10 \%$ weight loss (sibutramine vs. placebo) in the whole group was 3.5 (95\% CI 1.6-8.1) and 2.9 (95\% CI 1.2-6.8) compared with 6.8 (95\% CI 1.8-25.6) and 9.6 (95\% CI 1.7-53.8) (5 and $10 \%$ weight loss, respectively) in the CC group (sibutramine vs. control). In contrast, Grudell et al. [42] showed that $\mathrm{T}$ allele carriers (TT/TC) exhibited greater weight loss than CC genotype in a study of 181 overweight or obese patients in a double-blind randomized controlled trial of sibutramine or placebo for 12 weeks. More recently, Hsiao et al. [43] sought to clarify this issue using Asian obese subjects $(\mathrm{n}=131)$ who completed a 12 -week intervention of placebo or sibutramine treatment. Similar to both previous studies, weight loss on the whole-group level was greater in the sibutramine group versus placebo $(7.4 \pm 1.2$ vs. $3.5 \pm 1.3 \mathrm{~kg})$ after controlling for sex and baseline body weight and fat. Echoing the findings of Grudell et al. [42], TT and TC carriers lost significantly more weight on sibutramine compared to control, whereas CC carriers did not differ from control subjects in terms of body weight or fat loss [43]. 
PNMT

PNMT encodes the enzyme phenylethanolamine $\mathrm{N}$ methyltransferase which is responsible for the conversion of noradrenaline to adrenaline. Considering its function, polymorphisms in PNMT have the potential to influence response to sibutramine. In a study of obese women ( $\mathrm{n}=$ 94 3-month completers), Peters et al. [44] report that a polymorphism consisting of a $\mathrm{G}$ to $\mathrm{A}$ transition, located in the PNMT promoter $(-148$ from the transcription start site), was associated with sibutramine-induced weight loss success. Subjects homozygous for either A (AA) or G (GG) lost significantly more weight than G/A heterozygotes [44]. G(-184)A polymorphism is commonly linked with G(-390)A (not measured), and functional assays indicate that the combination of these SNPs results in decreased promoter activity [45]. However, association between the G(-184)A variant in PNMT and weight loss response to sibutramine could not be confirmed in a subsequent, albeit smaller, 12-week intervention including 22 subjects taking sibutramine and 21 taking placebo [46].

\section{SLC6A4}

SLC6A4 encodes a protein that transports serotonin from the synaptic cleft to the presynaptic neurons, thereby terminating its effects. A repeat-length polymorphism (5-HTTLPR) in the $5^{\prime}$ promoter region of this gene has been examined within the context of weight loss response to sibutramine. Alleles of the 5-HTTLPR promoter have either a short (S) or long (L) copy, with the $S$ allele resulting in lower transcriptional activity [47]. The SLC6A4 LS/ SS genotype was shown to be associated with significantly greater weight loss following sibutramine treatment $(6.1 \pm 1.0 \mathrm{~kg})$ compared with LS/SS or placebo $(0.1 \pm 0.9$ $\mathrm{kg})$. No effect of the LL genotype on weight loss responsiveness was reported [46]. The authors postulate that individuals with a partial functioning of the serotonin transporter have increased availability of serotonin for receptor-ligand interaction, leading to a more effective action of sibutramine [46].

\section{ADRA2A ( $\alpha 2 \mathrm{~A})$}

$\alpha 2 \mathrm{~A}$ adrenergic receptors are involved in presynaptic inhibition of noradrenaline release, and activation has been shown to increase food intake [48]. It has been proposed that genetic variation in $a 2 \mathrm{~A}$ leading to decreased norepinephrine uptake would complement reuptake inhibition by sibutramine and result in enhanced weight loss [42]. However, no effect of genotype at a2A-1291 C/G (rs1800544) on sibutramine- or placebo-induced weight loss following 12 weeks of treatment was observed [46].

\section{ADIPOQ}

Adiponectin is an adipose-derived plasma protein (adipokine) linked with glucose homeostasis and insulin sensitivity. Increased plasma adiponectin concentrations have been reported following sibutramine treatment [49]. Adiponectin is encoded by the ADIPOQ gene. ADIPOQ variant rs 266729 has received attention due to its association with obesity and type 2 diabetes [50]. In a study of obese Taiwanese patients taking sibutramine $(n=87)$ or placebo $(\mathrm{n}=44)$ for 12 weeks, C allele homozygosity was shown to associate with significantly greater body fat loss and total body weight loss with sibutramine treatment compared to the GG or GC genotypes [51].

\section{Safety PGx and Sibutramine}

\section{CYP Enzymes}

Risk/benefit in medicine approvals is of importance; however, individual safety is oftentimes at the core of regulator decisions. Safety PGx, distinct from efficacy PGx, seeks to determine underlying factors driving adverse response to a drug and, in combination with efficacy PGx, can identify segments of the population likely to experience a positive risk/benefit ratio. Again, the literature of safety PGx as it relates to obesity drugs centers around the study of sibutramine. In humans, sibutramine is rapidly metabolized to $\mathrm{N}$-mono-desmethyl sibutramine (M1) and $\mathrm{N}, \mathrm{N}$-di-desmethyl sibutramine (M2), and the in vivo effects are primarily due to the actions of these metabolites, rather than sibutramine itself [52]. Several CYP enzymes are involved in the metabolism of sibutramine including CYP3A4, CYP2B6, CYP3A5 and CYP2C19 [53]. These genes are highly polymorphic and impact the levels of substrates and their pharmacokinetic properties [54, 55]. A study investigating the impact of genotype at CYP2B6, CYP3A5 and CYP2C19 on pharmacokinetics of sibutramine found that genotype at CYP2B6 and CYP3A5 did not contribute to the pharmacokinetic variability of sibutramine. On the contrary, CYP2C19, which was thought to play a minor role based on in vitro data, was shown to significantly impact the disposition of sibutramine and the appearance of the M1 metabolite. Carriers of the PM genotype at CYP2C19 had a significantly greater area under the curve $(+252.2 \%)$ and $\mathrm{C}_{\max }(+179.8 \%)$ sibutramine in plasma than other genotypes. Additionally, the $\mathrm{C}_{\max }$ and area under the curve of the M1 metabolite was significantly raised [56]. A subsequent study investigated the impact of genotype at CYP2B6, and pharmacokinetics of sibutramine and active metabolites was conducted with 57 subjects each given a single dose of either 10 or $15 \mathrm{mg}$ with blood collected for $72 \mathrm{~h}$ after ad- 
ministration. Genotype at CYP2B6 did not significantly impact area under the concentration time curve or maximum plasma drug concentration; however, a relationship between the $C Y P 2 B 6^{*} 6$ allele and a lower metabolite clearance of the M1 metabolite was observed. No differences in blood pressure were observed across genotype groups [57]. These studies have highlighted the impact of variants in genes encoding CYP enzymes and sibutramine pharmacokinetics. However, the contribution of these variants to the development of adverse events has not been adequately addressed.

\section{Other Potential SNPs Impacting Drug Efficacy}

Although PGx studies for obesity drugs other than sibutramine are lacking, genetic variants in genes associated with drug mechanism of action with the potential to influence response have been identified.

\section{Orlistat}

SNPs have been identified in the gene encoding pancreatic lipase (PNLIP), the enzyme responsible for the hydrolysis of triglyceride in the intestine. Sequencing PNLIP exons in a cohort of patients with pancreatic lipase and control deficiency identified 3 silent SNPs associated with pancreatic lipase deficiency. Subsequent genotyping of Caucasian, Asian, African and Native American cohorts identified that two of these SNPs were relatively common in Caucasian populations, and one appears to be African decent specific [38]. Orlistat targets pancreatic lipase and inhibits its activity, thus impairing triacylglycerol hydrolysis and subsequent absorption by the intestine. Unabsorbed lipid is passed in the feces, and the presence of this excess lipid in the gastrointestinal tract is the cause of Orlistat-induced adverse effects. Hence, this variation has relevance for the treatment of individuals with Orlistat, as genotype at PNLIP may contribute to variability in triacylglycerol hydrolysis and so to the degree of efficacy and adverse effects experienced.

\section{Lorcaserin}

Lorcaserin is a $5-\mathrm{HT}_{2 \mathrm{C}}$ selective agonist. $5-\mathrm{HT}_{2 \mathrm{C}}$ receptors are expressed in the brain and neurotransmission via these receptors has been implicated in ingestive and appetite behaviors [58]. 5- $\mathrm{HT}_{2 \mathrm{C}}$ receptors are postsynaptic with classical 7-transmembrane spanning domains associated with G-protein coupled receptors and linked to phospholipase $\mathrm{A} 2$ and $\mathrm{C}$ [58]. $5-\mathrm{HT}_{2 \mathrm{C}}$ receptors are unique among the 7 transmembrane receptors in that $5-\mathrm{HT}_{2 \mathrm{C}}$ pre-mRNA is the subject of RNA editing [59]. The human brain exhibits diversity in the type of $5-\mathrm{HT}_{2 \mathrm{C}}$
mRNA expressed and this diversity and differences in editing can impact G-protein coupling and downstream intracellular signaling and has been demonstrated to decrease agonist potency [59]. Variability in regulation and expression of adenosine deaminases acting on RNA (ADARs) (editing machinery) as well as in $5-\mathrm{HT}_{2 \mathrm{C}}$ itself (editing template) could have a significant impact on response to treatment with $5-\mathrm{HT}_{2 \mathrm{C}}$ agonists [59]. Additionally, a number of SNPs (-995G/A, -759C/T and -697G/ $\mathrm{C})$ and a tandem repeat sequence (-1027GT) located in the $5-\mathrm{HT}_{2 \mathrm{C}}$ promoter give rise to a series of haplotypes associated with obesity and type 2 diabetes [60], and have also been reported to be associated with high receptor expression rates [61]. Although these SNPs have not been studied within the context of response to weight loss drugs which target $5-\mathrm{HT}_{2 \mathrm{C}}$ such as lorcaserin or sibutramine, these $5-\mathrm{HT}_{2 \mathrm{C}}$ polymorphisms have been associated with variability in response to antipsychotic drugs and the risk of antipsychotic-induced weight gain [58, 62]. Furthermore, the $5-\mathrm{HT}_{2 \mathrm{C}}$ gene product undergoes posttranslational modification leading to amino acid substitutions which can alter efficacy of interaction between receptor and $G$ protein and can decrease agonist binding efficacy (antagonist not affected) [58].

\section{Cannabinoid Receptor Type 1 Blockers}

Cannabinoid receptor type 1 (CB1) blockers such as rimonabant have been shown to decrease body weight in some individuals albeit with significant neuropsychiatric side effects. SNPs located within the gene encoding CB1 (CNR1) have been linked with obesity phenotypes [63]. There are currently no reports of the impact of genotype at CNR1 and weight loss response to CB1 blockers such as rimonabant. However, $\mathrm{CB} 1$ is also a target of psychiatric drugs, and genotype at rs 1049353 has been linked with response to antidepressant treatment. Specifically, G allele carriers (GG/AG) may be resistant to antidepressant treatment relative to AA genotype at rs1049353 [64].

\section{Glucagon-Like Peptide 1 Receptor Agonists}

It is possible that variability in Glucagon-Like Peptide 1 Receptor $(G L P-1 R)$ contributes to the variability in weight loss response to GLP-1 treatment (e.g. exenatide or other GLP-1 analogues) [24]. For example, a heterozygous GLP-1R missense polymorphism that resulted in a substitution of threonine 149 by methionine (T149M) and which was associated with diabetes has been identified [65] and studied in vitro [66]. This polymorphism was observed to reduce binding of GLP-1 and exendin- 4 [66]. In addition to downregulated agonist potencies, the 
polymorphic receptor induced significantly less cAMP production (GLP-1 and exendin-4 stimulated) cells compared to the wild type receptor [66].

\section{Building PGx into Drug Development - Prospective Efficacy PGx}

There are a number of cases where PGx information has been added successfully to a drug label after marketing. For example, the label of clopidogrel (Plavix) [67], used to prevent blood clots in patients recently suffering from myocardial infarction or stroke, was updated to include information on the impact of SNPs on CYP2C19 efficacy. This was based on postmarketing information linking a loss of function mutation in CYP2C19 to reduced antiplatelet response to clopidogrel and an increased risk of death or nonfatal myocardial infarction or stroke $[68,69]$. Abacavir (Ziagen), used in HIV infection, is another example of postmarketing PGx label changes to identify patients at risk of toxicity-related side effects [31]. Warfarin (Coumadin) has also been updated to include PGx information useful in the selection of a suitable therapeutic dose [31].

Although these postmarketing developments have significant benefit, the recognition of population subgroups before approval would be advantageous for patients and pharmaceutical companies alike. The utilization of PGx approaches early in the drug development pipeline may aid in optimal drug and dosing selection, as well as help to predict and select individual responders and nonresponders. The early identification of responders and nonresponders serves to increase confidence in a molecule and promote those with potential for further study [70]. This in turn increases the potential for obesity drug approvals, by enriching subsequent phase III trials for individuals likely to respond positively and by preempting populations in which the drug may be contraindicated due to an increased risk of adverse events. Achieving a greater weight loss may help to offset some of the risk associated with these drugs, improving the risk/benefit ratio. This enrichment also serves to decrease sample size in the larger phase III trials (due to larger effect sizes), thus reducing cost and time $[31,70]$. Ultimately, this can provide patients with earlier access to targeted, safer and more efficacious treatments.

A published example of this 'prospective efficacy PGx' [70] approach in action is the use of a GI181771X (GlaxoSmithKline), a cholecystokinin A1 (CCK-A1) receptor agonist, in the treatment of obesity. Cholecystoki-

Pharmacotherapy and Genes in Human Obesity
$\operatorname{nin}(\mathrm{CCK})$ is a gut hormone and neurotransmitter which is released from the I-cells of the small intestine in response to luminal nutrients [71]. CCK promotes digestion [71] and in addition functions as an anorectic, suppressing food intake by decreasing meal size [72-74]. Roses [75] described a small phase II-A trial of obese individuals randomized to receive placebo $(\mathrm{n}=41)$ or drug $(\mathrm{n}=40)$. Following the 2 -month treatment period, a clear group of hyperresponders, losing between 5 and $9 \%$ of their body weight, could be distinguished, showing that this compound was efficacious in a targeted population. This study contained a significant PGx element, and genotype at 112 SNPs (in 21 candidate genes) which represented potential polymorphic sites in the mechanism of action were tested. An analysis of allele segregation of the 21 candidate genes across the drug and placebo populations identified 3 SNPs that segregated with the drug response variation. One allele of each of these 3 SNPs (2 related to the drug-proposed mechanism of action and 1 related to obesity generally) associated with the hyperresponder group (denoted as 2-2 homozygotes) and the other allele associated with the nonresponder group (denoted as 1-1 homozygotes). The hyperresponders lost on average $3.3 \mathrm{~kg}$ during the study and nonresponders gained an average of $1.3 \mathrm{~kg} .1-2$ heterozygotes (considered as potential responders) fell in the middle for weight change. This example represents a proof-of-concept PGx study which was taken forward into a larger phase II-B trial. However, failure to adequately incorporate this preliminary PGx data into the study design of the subsequent trial [75] resulted in a negative outcome, in that there was no significant weight loss difference in the drug-treated compared with the placebo-treated groups [76]. In addition to GlaxoSmithKline, other pharmaceutical companies also had CCK-1 receptor agonists in development and did not report taking advantage of genetic differences to better understand and potentially improve the efficacy and risk/benefit of these compounds.

The rationale of the company at the time to incorporate data from the PGx phase II-A trials in subsequent larger trials may be understood by the fact that the FDA 'Voluntary Exploratory Data Submission' (VXDS) was not yet in existence, hence this change in design would have represented a departure from existing process [75]. The newer guidance on this area from the FDA, in conjunction with the European Agency for the Evaluation of Medicinal Products (EMEA), and the so-called 'safe harbor' for the submission of pharmacogenomic data [77], facilitates communication between the sponsor and the regulators early in the process. The creation of this review 
infrastructure allows the sponsor to gain a clear understanding of how the FDA will react to genomic, or indeed other 'omics' data, and can guide future planning steps on the road to registration [77].

\section{Conclusions}

Although application of PGx testing may not be as prevalent in primary care as it was predicted to be at this stage after the completion of the human genome project [78], the relevance of genomic analysis and its relationship with therapeutic drug responses is becoming more prevalent in the consumer/public mindset. Many directto-consumer genotyping services now provide information on genotype and adverse event risk as well as drug efficacy. Although these may currently be premature and limited in scope and utility, this is a growth area and the adoption of next-generation sequencing technologies will significantly enhance the information available to consumers [79].

The majority of PGx studies in the area of obesity to date have been hampered by small sample sizes which are most likely underpowered. Additional issues include retrospective genotyping, meaning that studies were not powered specifically for the analysis of a genotype effect, analysis of a small set of targeted candidate genes based on proposed mechanism of action, and analysis of one or very few genetic variants at a given locus [24]. Published reports of PGx and obesity drugs have been carried out largely at academic or clinical centers with only one report highlighting the use of PGx in the drug development pipeline. This reflects the problem on the ground of variable response to drug treatment of obesity and the attempt to understand and predict response or nonresponse to therapy, and the need for safer more efficacious targeted therapies.

Considering the direct negative impact of obesity on health and health care costs, it is essential that effective, safe and long-term treatments are developed. Treating a complex, multi-factorial condition such as obesity with a single drug and expecting it to be safe and efficacious in all obese individuals is unrealistic and to date has failed to effect positive change in obesity prevalence. Pharmacotherapies have a clear place in obesity management. Lifestyle changes alone are difficult to maintain, and the inclusion of drugs targeting food intake and energy expenditure pathways has the potential to enhance and maintain weight loss success. The polygenic and multifaceted nature of weight gain and obesity can make the development of treatment plans problematic. However, it is necessary to accept and address this complexity, with the goal of understanding which segments of a population (representing disease subtypes) will respond to treatment by either identifying underlying genetic drivers or characterizing response phenotypes. Targeting interventions at those who will benefit from them most in a safe manner may improve compliance and ultimately will play a meaningful role in the management of obesity.

\section{References}

1 World Health Organization: Obesity and Overweight. Fact Sheet No. 311, 2012.

2 Trust for America's Health: $\mathrm{F}$ as in Fat: How Obesity Threatens America's Future. Washington, DC, Trust for America's Health, 2011

-3 Wang Y, Beydoun MA, Liang L, Caballero B, Kumanyika SK: Will all Americans become overweight or obese? Estimating the progression and cost of the US obesity epidemic. Obesity (Silver Spring) 2008;16:2323-2330.

4 McPherson K, Marsh T, Brown M: Foresight Report. Tackling Obesities: Future Choices Modelling Future Trends in Obesity and Their Impact on Health, ed 2. London, Government Office for Science, 2007.

5 Loos RJ: Genetic determinants of common obesity and their value in prediction. Best Pract Res Clin Endocrinol Metab 2012;26: 211-226.
6 Dubern B, Clement K: Leptin and leptin receptor-related monogenic obesity. Biochimie 2012;94:2111-2115.

7 Sandholt CH, Hansen T, Pedersen O: Beyond the fourth wave of genome-wide obesity association studies. Nutr Diabetes 2012;2:e37.

8 Loos RJ, Lindgren CM, Li S, Wheeler E, Zhao JH, Prokopenko I, et al: Common variants near MC4R are associated with fat mass, weight and risk of obesity. Nat Genet 2008;40: 768-775.

\9 Frayling TM, Timpson NJ, Weedon MN, Zeggini E, Freathy RM, Lindgren CM, et al: A common variant in the FTO gene is associated with body mass index and predisposes to childhood and adult obesity. Science 2007; 316:889-894
10 National Institutes of Health, National Heart, Lung, and Blood Institute, North American Association for the Study of Obesity: The Practical Guide: Identification, Evaluation, and Treatment of Overweight and Obesity in Adults. NIH Publication No. 00-4084, 2000.

11 Ribisl PM, Gaussoin SA, Lang W, Bahnson J, Connelly SA, Horton ES, et al: Lifestyle intervention improves heart rate recovery from exercise in adults with type 2 diabetes: results from the Look AHEAD study. J Obes 2012; 2012:309196

12 Unick JL, Beavers D, Jakicic JM, Kitabchi AE, Knowler WC, Wadden TA, et al: Effectiveness of lifestyle interventions for individuals with severe obesity and type 2 diabetes: results from the Look AHEAD trial. Diabetes Care 2011;34:2152-2157. 
$\checkmark 13$ Orchard TJ, Temprosa M, Barrett-Connor E, Fowler SE, Goldberg RB, Mather KJ, et al: Long-term effects of the Diabetes Prevention Program interventions on cardiovascular risk factors: a report from the DPP Outcomes Study. Diabet Med 2013;30:46-55.

14 Rosenbaum M, Leibel RL: Adaptive thermogenesis in humans. Int J Obes (Lond) 2010; 34(suppl 1):S47-S55.

15 FDA: FDA-approved diabetes medicines http://www.fda.gov/ForConsumers/ByAudience/ForPatientAdvocates/DiabetesInfo/ ucm294713.htm (accessed January 25, 2013).

16 FDA: High blood pressure - medicines to help you. http://www.fda.gov/ForConsumers/ByAudience/ForWomen/ucm 118594 htm (accessed January 25, 2013).

17 Vilsboll T, Christensen M, Junker AE, Knop FK, Gluud LL: Effects of glucagon-like peptide-1 receptor agonists on weight loss: systematic review and meta-analyses of randomised controlled trials. BMJ 2012; 344:d7771.

18 Gadde KM, Allison DB, Ryan DH, Peterson CA, Troupin B, Schwiers ML, et al: Effects of low-dose, controlled-release, phentermine plus topiramate combination on weight and associated comorbidities in overweight and obese adults (CONQUER): a randomised, placebo-controlled, phase 3 trial. Lancet 2011; 377:1341-1352.

19 Van Gaal LF, Rissanen AM, Scheen AJ, Ziegler O, Rossner S: Effects of the cannabinoid-1 receptor blocker rimonabant on weight reduction and cardiovascular risk factors in overweight patients: 1-year experience from the RIO-Europe study. Lancet 2005;365: 1389-1397.

-20 Fidler MC, Sanchez M, Raether B, Weissman NJ, Smith SR, Shanahan WR, et al: A one-year randomized trial of lorcaserin for weight loss in obese and overweight adults: the BLOSSOM trial. J Clin Endocrinol Metab 2011;96 3067-3077.

21 Hemo B, Endevelt R, Porath A, Stampfer MJ, Shai I: Adherence to weight loss medications; post-marketing study from HMO pharmacy data of one million individuals. Diabetes Res Clin Pract 2011;94:269-275.

22 Johansson K, Neovius K, DeSantis SM, Rossner S, Neovius M: Discontinuation due to adverse events in randomized trials of orlistat, sibutramine and rimonabant: a meta-analysis. Obes Rev 2009;10:564-575.

23 Schadt EE, Sachs A, Friend S: Embracing complexity, inching closer to reality. Sci STKE 2005;2005:pe40.

24 Vella A, Camilleri M: Pharmacogenetics: potential role in the treatment of diabetes and obesity. Expert Opin Pharmacother 2008;9: 1109-1119.

25 Ara R, Blake L, Gray L, Hernandez M, Crowther M, Dunkley A, et al: What is the clinical effectiveness and cost-effectiveness of using drugs in treating obese patients in primary care? A systematic review. Health Technol Assess 2012;16:III-XIV, 1-195.
Wadden TA, Berkowitz RI, Womble LG, Sarwer DB, Phelan S, Cato RK, et al: Randomized trial of lifestyle modification and pharmacotherapy for obesity. N Engl J Med 2005;353: 2111-2120.

-27 Van Gaal LF, Broom JI, Enzi G, Toplak H: Efficacy and tolerability of orlistat in the treatment of obesity: a 6-month dose-ranging study. Orlistat Dose-Ranging Study Group. Eur J Clin Pharmacol 1998;54:125132.

28 Smith SR, Weissman NJ, Anderson CM, Sanchez M, Chuang E, Stubbe S, et al: Multicenter, placebo-controlled trial of lorcaserin for weight management. N Engl J Med 2010; 363:245-256.

29 Pi-Sunyer FX, Aronne LJ, Heshmati HM, Devin J, Rosenstock J: Effect of rimonabant, a cannabinoid-1 receptor blocker, on weight and cardiometabolic risk factors in overweight or obese patients: RIO-North America: a randomized controlled trial. JAMA 2006; 295:761-775.

30 International Conference on Harmonisation of Technical Requirements for Registration of Pharmaceuticals for Human Use: ICH harmonised tripartite guideline: definitions for genomic biomarkers, pharmacogenomics, pharmacogenetics, genomic data and sample coding categories. E15. 2007 http://www.ich. org/fileadmin/Public_Web_Site/ICH_Products/Guidelines/Efficacy/E15/Step4/E15 Guideline.pdf (accessed January 25, 2013).

31 US Department of Health and Human Services, FDA, CDER, CBER, CDRH: Guidance for industry: clinical pharmacogenomics: premarket evaluation in early-phase clinical studies and recommendations for labeling. http://www.fda.gov/downloads/Drugs/GuidanceComplianceRegulatoryInformation/ Guidances/UCM337169.pdf (accessed August 5,2013$)$.

32 Muller DJ, Chowdhury NI, Zai CC: The pharmacogenetics of antipsychotic-induced adverse events. Curr Opin Psychiatry 2013;26: 144-150.

33 Lett TA, Wallace TJ, Chowdhury NI, Tiwari AK, Kennedy JL, Muller DJ: Pharmacogenetics of antipsychotic-induced weight gain: review and clinical implications. Mol Psychiatry 2012;17:242-266.

34 Finer N: Sibutramine: its mode of action and efficacy. Int J Obes Relat Metab Disord 2002; 26(suppl 4):S29-S33.

35 Halford JC, Harrold JA: 5-HT(2C) receptor agonists and the control of appetite. Handb Exp Pharmacol 2012;209:349-356.

36 Siffert W, Forster P, Jockel KH, Mvere DA, Brinkmann B, Naber C, et al: Worldwide ethnic distribution of the $\mathrm{G}$ protein beta3 subunit $825 \mathrm{~T}$ allele and its association with obesity in Caucasian, Chinese, and Black African individuals. J Am Soc Nephrol 1999;10:1921-1930.

37 Gutersohn A, Naber C, Muller N, Erbel R, Siffert W: G protein beta3 subunit 825 TT genotype and post-pregnancy weight retention. Lancet 2000;355:1240-1241.
38 Hegele RA, Anderson C, Young TK, Connelly PW: G-protein beta3 subunit gene splice variant and body fat distribution in Nunavut Inuit. Genome Res 1999;9:972-977.

- 39 Siffert W, Rosskopf D, Siffert G, Busch S, Moritz A, Erbel R, et al: Association of a human G-protein beta3 subunit variant with hypertension. Nat Genet 1998;18:45-48.

40 Hauner H, Meier M, Jockel KH, Frey UH, Siffert W: Prediction of successful weight reduction under sibutramine therapy through genotyping of the G-protein beta3 subunit gene (GNB3) C825T polymorphism. Pharmacogenetics 2003;13:453-459.

41 Siffert W, Naber C, Walla M, Ritz E: G protein beta3 subunit $825 \mathrm{~T}$ allele and its potential association with obesity in hypertensive individuals. J Hypertens 1999;17:1095-1098.

42 Grudell AB, Sweetser S, Camilleri M, Eckert DJ, Vazquez-Roque MI, Carlson PJ, et al: A controlled pharmacogenetic trial of sibutramine on weight loss and body composition in obese or overweight adults. Gastroenterology 2008;135:1142-1154.

43 Hsiao DJ, Wu LS, Huang SY, Lin E: Weight loss and body fat reduction under sibutramine therapy in obesity with the C825T polymorphism in the GNB3 gene. Pharmacogenet Genomics 2009;19:730-733.

44 Peters WR, MacMurry JP, Walker J, Giese RJ Jr, Comings DE: Phenylethanolamine Nmethyltransferase G-148A genetic variant and weight loss in obese women. Obes Res 2003;11:415-419.

45 Ji Y, Salavaggione OE, Wang L, Adjei AA Eckloff B, Wieben ED, et al: Human phenylethanolamine N-methyltransferase pharmacogenomics: gene re-sequencing and functional genomics. J Neurochem 2005;95:17661776.

46 Vazquez Roque MI, Camilleri M, Clark MM, Tepoel DA, Jensen MD, Graszer KM, et al: Alteration of gastric functions and candidate genes associated with weight reduction in response to sibutramine. Clin Gastroenterol Hepatol 2007;5:829-837.

47 Lesch KP, Bengel D, Heils A, Sabol SZ, Greenberg BD, Petri S, et al: Association of anxietyrelated traits with a polymorphism in the serotonin transporter gene regulatory region. Science 1996;274:1527-1531.

48 Wellman PJ: Norepinephrine and the control of food intake. Nutrition 2000;16:837-842.

49 Kim DM, Yoon SJ, Ahn CW, Cha BS, Lim SK, Kim KR, et al: Sibutramine improves fat distribution and insulin resistance, and increases serum adiponectin levels in Korean obese nondiabetic premenopausal women. Diabetes Res Clin Pract 2004;66(suppl 1):S139 S144.

50 Siitonen N, Pulkkinen L, Lindstrom J, Kolehmainen M, Eriksson JG, Venojarvi M, et al: Association of ADIPOQ gene variants with body weight, type 2 diabetes and serum adiponectin concentrations: the Finnish Diabetes Prevention Study. BMC Med Genet 2011; 12:5.
Pharmacotherapy and Genes in Human Obesity
Hum Hered 2013;75:116-126 DOI: $10.1159 / 000349975$ 
51 Hsiao TJ, Wu LS, Huang SY, Lin E: A common variant in the adiponectin gene on weight loss and body composition under sibutramine therapy in obesity. Clin Pharmacol 2010;2:105-110.

52 Luscombe GP, Hopcroft RH, Thomas PC, Buckett WR: The contribution of metabolites to the rapid and potent down-regulation of rat cortical beta-adrenoceptors by the putative antidepressant sibutramine hydrochloride. Neuropharmacology 1989;28:129-134.

-53 Bae SK, Cao S, Seo KA, Kim H, Kim MJ, Shon $\mathrm{JH}$, et al: Cytochrome P450 2B6 catalyzes the formation of pharmacologically active sibutramine (N-\{1-[1-(4-chlorophenyl) cyclobutyl]-3-methylbutyl -N,N-dimethylamine) metabolites in human liver microsomes. Drug Metab Dispos 2008;36:16791688.

-54 Ingelman-Sundberg M, Sim SC, Gomez A, Rodriguez-Antona C: Influence of cytochrome P450 polymorphisms on drug therapies: pharmacogenetic, pharmacoepigenetic and clinical aspects. Pharmacol Ther 2007; 116:496-526

-55 Zanger UM, Klein K, Saussele T, Blievernicht J, Hofmann MH, Schwab M: Polymorphic CYP2B6: molecular mechanisms and emerging clinical significance. Pharmacogenomics 2007;8:743-759.

56 Kim KA, Song WK, Park JY: Association of CYP2B6, CYP3A5, and CYP2C19 genetic polymorphisms with sibutramine pharmacokinetics in healthy Korean subjects. Clin Pharmacol Ther 2009;86:511-518.

57 Chung JY, Jang SB, Lee YJ, Park MS, Park K Effect of CYP2B6 genotype on the pharmacokinetics of sibutramine and active metabolites in healthy subjects. J Clin Pharmacol 2011;51: 53-59.

58 Reynolds GP, Templeman LA, Zhang ZJ: The role of 5-HT2C receptor polymorphisms in the pharmacogenetics of antipsychotic drug treatment. Prog Neuropsychopharmacol Biol Psychiatry 2005;29:1021-1028.

-59 Werry TD, Loiacono R, Sexton PM, Christopoulos A: RNA editing of the serotonin 5 HT2C receptor and its effects on cell signalling, pharmacology and brain function. Pharmacol Ther 2008;119:7-23.

-60 Yuan X, Yamada K, Ishiyama-Shigemoto S, Koyama W, Nonaka K: Identification of polymorphic loci in the promoter region of the serotonin 5-HT2C receptor gene and their association with obesity and type II diabetes. Diabetologia 2000;43:373-376.
61 Chang CJ, Tzeng TF, Liou SS, Chang YS, Liu IM: Kaempferol regulates the lipid-profile in high-fat diet-fed rats through an increase in hepatic PPARalpha levels. Planta Med 2011; 77:1876-1882.

62 Arranz MJ, Rivera M, Munro JC: Pharmacogenetics of response to antipsychotics in patients with schizophrenia. CNS Drugs 2011; 25:933-969.

63 Russo P, Strazzullo P, Cappuccio FP, Tregouet DA, Lauria F, Loguercio M, et al: Genetic variations at the endocannabinoid type $1 \mathrm{re}$ ceptor gene (CNR1) are associated with obesity phenotypes in men. J Clin Endocrinol Metab 2007;92:2382-2386.

64 Domschke K, Dannlowski U, Ohrmann P, Lawford B, Bauer J, Kugel H, et al: Cannabinoid receptor 1 (CNR1) gene: impact on antidepressant treatment response and emotion processing in major depression. Eur Neuropsychopharmacol 2008;18:751-759.

65 Tokuyama Y, Matsui K, Egashira T, Nozaki O, Ishizuka T, Kanatsuka A: Five missense mutations in glucagon-like peptide 1 receptor gene in Japanese population. Diabetes Res Clin Pract 2004;66:63-69.

66 Beinborn M, Worrall CI, McBride EW, Kopin AS: A human glucagon-like peptide-1 receptor polymorphism results in reduced agonist responsiveness. Regul Pept 2005;130:1-6.

67 FDA: Highlights of prescribing information. Plavix (clopidogrel bisulfate) tablets. 2011. http://www.accessdata.fda.gov/drugsatfda docs/label/2011/020839s055lbl.pdf (accessed January 25, 2013).

68 Mega JL, Close SL, Wiviott SD, Shen L, Hockett RD, Brandt JT, et al: Cytochrome p-450 polymorphisms and response to clopidogrel. N Engl J Med 2009;360:354-362.

69 Mega JL, Simon T, Collet JP, Anderson JL, Antman EM, Bliden K, et al: Reduced-function CYP2C19 genotype and risk of adverse clinical outcomes among patients treated with clopidogrel predominantly for PCI: a meta-analysis. JAMA 2010;304:1821-1830.

70 Roses AD: Pharmacogenetics and drug development: the path to safer and more effective drugs. Nat Rev Genet 2004;5:645-656.

71 Simpson K, Parker J, Plumer J, Bloom S: CCK, PYY and PP: the control of energy balance. Handb Exp Pharmacol 2012;209:209-230.
72 Kissileff HR, Pi-Sunyer FX, Thornton J, Smith GP: C-terminal octapeptide of cholecystokinin decreases food intake in man. Am J Clin Nutr 1981;34:154-160.

73 Pi-Sunyer X, Kissileff HR, Thornton J, Smith GP: C-terminal octapeptide of cholecystokinin decreases food intake in obese men. Physiol Behav 1982;29:627-630.

74 Gibbs J, Young RC, Smith GP: Cholecystokinin decreases food intake in rats. J Comp Physiol Psychol 1973;84:488-495.

75 Roses AD: Stimulation of cholecystokinin-A receptors with Gl181771X: a failed clinical trial that did not test the pharmacogenetic hypothesis for reduction of food intake. Clin Pharmacol Ther 2009;85:362-365.

76 Jordan J, Greenway FL, Leiter LA, Li Z, Jacobson P, Murphy K, et al: Stimulation of cholecystokinin-A receptors with GI181771X does not cause weight loss in overweight or obese patients. Clin Pharmacol Ther 2008;83:281287.

77 Orr MS, Goodsaid F, Amur S, Rudman A, Frueh FW: The experience with voluntary genomic data submissions at the FDA and a vision for the future of the voluntary data submission program. Clin Pharmacol Ther 2007; 81:294-297.

78 Swen JJ, Guchelaar HJ: Just how feasible is pharmacogenetic testing in the primary healthcare setting? Pharmacogenomics 2012; 13:507-509.

79 Chua EW, Kennedy MA: Current state and future prospects of direct-to-consumer pharmacogenetics. Front Pharmacol 2012;3:152.

80 Derosa G, Maffioli P: Efficacy and safety profile evaluation of acarbose alone and in association with other antidiabetic drugs: a systematic review. Clin Ther 2012;34:12211236.

81 Kang JG, Park CY, Kang JH, Park YW, Park SW: Randomized controlled trial to investigate the effects of a newly developed formulation of phentermine diffuse-controlled release for obesity. Diabetes Obes Metab 2010; 12:876-882.

82 Cameron F, Whiteside G, McKeage K: Phentermine and topiramate extended release (Qsymia): first global approval. Drugs 2012; 72:2033-2042.

83 Christensen R, Kristensen PK, Bartels EM, Bliddal H, Astrup A: Efficacy and safety of the weight-loss drug rimonabant: a meta-analysis of randomised trials. Lancet 2007;370:17061713. 